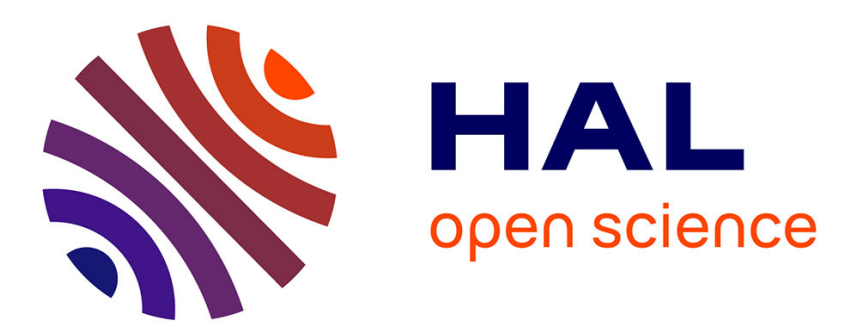

\title{
Seismic vulnerability assessment to slight damage based on experimental modal parameters
}

\author{
Clotaire Michel, Philippe Gueguen, Matthieu Causse
}

\section{To cite this version:}

Clotaire Michel, Philippe Gueguen, Matthieu Causse. Seismic vulnerability assessment to slight damage based on experimental modal parameters. Earthquake Engineering and Structural Dynamics, 2012, 41 (1), pp.81-98. 10.1002/eqe.1119 . hal-00673135

\section{HAL Id: hal-00673135 \\ https://hal.science/hal-00673135}

Submitted on 22 Feb 2012

HAL is a multi-disciplinary open access archive for the deposit and dissemination of scientific research documents, whether they are published or not. The documents may come from teaching and research institutions in France or abroad, or from public or private research centers.
L'archive ouverte pluridisciplinaire HAL, est destinée au dépôt et à la diffusion de documents scientifiques de niveau recherche, publiés ou non, émanant des établissements d'enseignement et de recherche français ou étrangers, des laboratoires publics ou privés. 


\section{Seismic vulnerability assessment to slight dam- age based on experimental modal parameters}

Clotaire Michel $^{1,3}$, Philippe Gueguen ${ }^{2}$, Matthieu Causse ${ }^{2}$

1 Applied Computing and Mechanics Laboratory (IMAC), Ecole Polytechnique Fédérale de Lausanne, Switzerland

2 ISTerre, Universite Joseph Fourier - Grenoble 1, CNRS, IFSTTAR, BP 53, F38041 Grenoble Cedex 9, France

3 Swiss Seismological Service, Swiss Federal Institute of Technology, Zuerich, Switzerland.

Michel C., Gueguen P., Causse M. 2011. Seismic vulnerability assessment to slight damage based on experimental modal parameters, Earthquake Engineering and Structural Dynamics, 41(1) : 81-98, DOI : 10.1002/eqe.1119 


\begin{abstract}
The aim of this paper is to adjust behaviour models for each class of structure for vulnerability assessment by using ambient vibration. A simple model based on frequencies, mode shapes and damping, taken from ambient vibrations, allows computation of the response of the structures and comparison of inter-storey drifts with the limits found in the literature for the slight damage grade, considered here as the limit of elastic behaviour. Two complete methodologies for building fragility curves are proposed: (1) using a multi-degree of freedom system including higher modes and full seismic ground motion, (2) using a single-degree of freedom model considering the fundamental mode $f_{0}$ of the structure and ground motion displacement response spectra $S_{D}\left(f_{0}\right)$. These two methods were applied to the city of Grenoble, where 60 buildings were studied. Fragility curves for slight damage were derived for the various masonry and reinforced concrete classes of buildings. A site-specific earthquake scenario, taking into account local site conditions, was considered, corresponding to an $M_{L}=5.5$ earthquake at a distance of $15 \mathrm{~km}$. The results show the benefits of using experimental models to reduce variability of the slight damage fragility curve. Moreover, by introducing the experimental modal model of the buildings, it is possible to improve seismic risk assessment at an overall scale (the city) or a local scale (the building) for the first damage grade (slight damage). This level of damage, of great interest for moderate seismic prone
\end{abstract}


regions, may contribute to the seismic loss assessment.

Keywords: Vulnerability, ambient vibrations, fragility curves, slight damage, Grenoble 


\section{Introduction}

In seismic prone regions, a full seismic risk analysis is generally represented as the economic and social losses of a potential seismic event. Its estimation requires contributions from several scientific disciplines for assessing seismic ground motion (including probabilistic assessment and site effects), the building response and its vulnerability in order to predict the ultimate damage and fatalities, and the economic and social consequences in the area in question. Over the last few decades, efforts have been made in moderate seismic regions (e.g., U.K., France, Switzerland, Spain, Portugal, etc.) to update Eurocode 8 [1], by improving the seismic hazard evaluation using probabilistic seismic hazard assessment (PSHA) methods, and by including recent knowledge on structural dynamics theory. Nevertheless, most losses produced by earthquakes throughout the world are due to deficient seismic behaviour in existing buildings in spite of improvements made to seismic codes [2]. A critical step in seismic risk assessment is therefore to be able to predict the expected damage of a given earthquake in existing structures. This may be of great interest to local or regional authorities in preparing for earthquakes, emergency response planning and risk mitigation.

In the literature (see [3] for a complete review), the first vulnerability methods were developed in strong seismic regions which had already suffered destructive earthquakes (e.g., [4], [5], [6], [7]). They were based on post-seismic inventories used to 
adjust continuous (Vulnerability Functions VF) or discrete (Damage Probability Matrices DPM) functions of seismic damage. DPM give the conditional probability of obtaining a specific damage level for a given level of hazard severity while VF provide average damage for a given level of ground motion. Both are established for building typology classes, modulated in some cases by qualitative structural, geometric and constructive parameters surveyed in the field [6], [8]. The level of damage (from no damage to collapse) is expressed by a damage scale representing the state of the structures at the end of the shaking. These methods were preferred in the past because the cost of wide area studies is relatively low due to the low number of parameters taken for each building and damage observations can be used to adjust vulnerability functions. However, they are valid statistically only, therefore on wide areas.

In moderate seismic regions, because of the lack of recent destructive earthquakes, one solution can be to import and adapt methods from others regions (e.g. [9], [10], [11]). Nevertheless, this analysis can be biased by previous local structural design and building practices and there will be some epistemic uncertainties [12]. Moreover, in these countries, there are no recent seismic ground motion recordings from major earthquakes to adjust the vulnerability functions.

So-called second level methods also exist, for example HAZUS [7] or Risk-UE [13] methods based on capacity and fragility curves of buildings obtained by modelling 
methods (e.g., pushover analyses, etc.). These curves are provided for each class of building typology and ground motion may be expressed by response spectrum (acceleration, displacement) or peak ground motion. The fragility curves approach is thus very well suited to the current assessment of seismic hazard (probabilistic or deterministic) based upon instrumental ground-motion measures and includes all uncertainties (including hazard and vulnerability) for evaluating regional seismic risk. However, for existing buildings, the adjustment of structural models must assume a large set of unknown parameters influencing the response of such buildings and introducing a large range of errors and epistemic uncertainties, generally due to the lack of structural plans, ageing and structural design. One solution to reduce these epistemic uncertainties is to perform ambient vibration tests in buildings, providing an estimate of the elastic modal parameters of structures (resonance frequencies, damping ratios and modal shapes). Recently, Boutin et al. [14] provided an integrity threshold-based method in the elastic domain, corresponding to the end of the elastic response of structures, just before damage occurs. They used a structural model deduced from ambient vibration recordings. Since Omori at the beginning of the 20th century [15], there has been an abundance of scientific literature on the interests of such experiments, which have been widely used by civil engineering, engineering seismology and earthquake engineering communities to monitor structures [16], to calibrate the elastic properties used 
by modellers $[17,18,19]$, to compare building response under weak and strong motions $[20,21,22,23,24]$ and to estimate seismic damage after strong earthquakes [16], [25], [26]. Since the first ambient vibration experiments, efforts have been made on signal processing methods, known as modal analysis methods, as well as on the development of acquisition systems to improve recording quality [27], [28]. The major drawback of using ambient vibrations is the scaling effects between weak and strong building motion. The non-linear behaviour of structures under strong motion may introduce variations of the modal parameters and influence their seismic response. Nevertheless, while an estimation of the highest damage grades (partial or total collapse) is of great interest in strong seismic regions, the first level of damage (slight damage) may be more relevant to weak seismic regions [14]. A particular application may be the loss estimation for seismicity induced by Enhanced Geothermal Systems [29]. It may be important to know whether a moderate earthquake can produce at least slight damage (scenario or real time evaluation), to define the retrofit priorities in a set of buildings in relation to the building code and to enable the introduction of relevant information into nonlinear methods useful for high damage grades. Furthermore, having been built before the current seismic codes, the ductility of almost all existing buildings may be much lower than the ductility of recently designed buildings. This means that the first grade of damage will be of interest in terms of the damage expected. 
The main aim of this paper is to show how the modal model extracted from ambient vibrations may contribute to assessing the vulnerability of existing buildings. We consider a threshold-based method for the probability function of the first damage grade (fragility curve). The methodology proposed to compute the fragility curves of the slight damage state is described first. The process (recordings, modal analysis using the Frequency Domain Decomposition method, modelling and finally fragility estimation) is then described and applied to three RC high-rise structures built towards the end of the 1960s in Grenoble (France). The method is subsequently applied to the whole of Grenoble, establishing fragility curves for each typology class in Grenoble. Finally, an earthquake scenario and the distribution of expected damage throughout the city are computed.

\section{Modal analysis using ambient vibrations}

Ambient vibrations in buildings are produced by the wind (low frequencies $<1 \mathrm{~Hz}$ ), internal sources (machinery, lift at high frequencies) and seismic noise (broadband). Ambient vibrations have been commonly used to monitor structures in civil, mechanical and aerospace engineering communities for a long time. Omori was the first to apply this technique to earthquake engineering in the early 20th century in Japan [15] to evaluate how existing buildings would move to resist against earth- 
quakes. Carder [30] was also a precursor, recording ambient vibrations in 336 buildings in California for the U.S. Coast and Geodetic survey after the 1933 Long Beach earthquake. His analysis is the basis for formulas giving the period of buildings as a function of their dimension in US design codes. Trifunac [20] confirmed the interest of ambient vibrations, considering the low cost of recording and the reliability of the associated results compared to active experiments (e.g., shaker, pull-out-test, explosion, etc.). Since then, and in parallel to the development of sensitive, portable acquisition systems, many experiments on the relevance of ambient vibrations in structure were conducted in the nineties by the civil engineering community [17], [18], [19], [31], [32].

Assuming linear behaviour, the motion of structures can be decomposed into modes of vibration. Recently, a large number of new algorithms have been provided for processing ambient vibrations for the purposes of operational modal analysis. Unlike Input-Output techniques for which building response is evaluated by knowing both the input signal (for example, seismic ground motion) and the output signal corresponding to building motion (for example, recorded on the roof), ambient vibration based methods, or Output-Only Modal Analysis methods, consider the input as unknown [33]. Among them, the Frequency Domain Decomposition (FDD) method used in this study was selected because of its relevance and applicability to the buildings [19], [24], [34], [35] . FDD is able to decompose modes, even when 
they are not sufficiently separate, which is often the case in existing buildings. It is a non-parametric method, which means that no a priori model is needed to process ambient vibration data. The Power Spectral Density matrices, i.e. the Fourier Transform of the correlation matrices, are estimated first using the Welch method [36], i.e. Fourier Transforms of overlapping regular windows of the signal are averaged. In a second step, a singular value decomposition of these matrices is performed. Brincker et al. [35] showed that at a resonance frequency, the first singular value exhibits a peak that corresponds to frequency and the modal shape is the corresponding singular vector (Fig. 1). By comparing the mode shape at the peak with the mode shapes of the surrounding frequency values, the SDOF density function can be selected in the singular values using the Modal Assurance Criterion (MAC), computed as follows:

$$
\operatorname{MAC}\left(\Phi_{1}, \Phi_{2}\right)=\frac{\left|\Phi_{1}^{H} \Phi_{2}\right|^{2}}{\left|\Phi_{1}^{H} \Phi_{1}\right|\left|\Phi_{2}^{H} \Phi_{2}\right|}
$$

where two modal shapes $\Phi_{1}$ and $\Phi_{2}$ are compared and $H$ denotes the complex conjugate and transpose. A MAC value greater than $80 \%$ indicates that the point still belongs to the mode density function, even on the second singular value (Fig. 1). The SDOF density function then represents the Transfer Function of the SingleDegree-Of-Freedom (SDOF) system, characterized by the peak frequency of the mode bell. Its inverse Fourier Transform provides the Impulse Response Function 
of the mode [37] and the damping value is then computed using the decrement method [38]. Thus, FDD gives the structural modes, including resonance frequency $\omega$, damping ratio $\zeta$ and modal shape $\Phi$.

\section{Experimental modal model and fragility curves}

For a given structure, the ambient vibration based model is defined from modal parameters to predict the building elastic response to weak seismic ground motion. The model is therefore only valid until the end of the structure integrity, i.e. the first level of damage. Rosseto and Elnashai [39] compared the damage grade levels documented in different scales (e.g., MSK, EMS98, HAZUS) for each class of building. Our study only considers slight damage as defined in HAZUS [7]. The method proposed here is divided into three steps: construction of the building model using experimental modal parameters, definition of the threshold damage criterion and computation of the fragility curve corresponding to the slight damage level.

\subsection{Step 1- Experimental modal modelling}

Bearing in mind the need for a method adapted to the scale of a city, we chose a simple 1D linear lumped mass model. One major advantage is that it has an analytical solution depending only on modal parameters. The displacement vector 

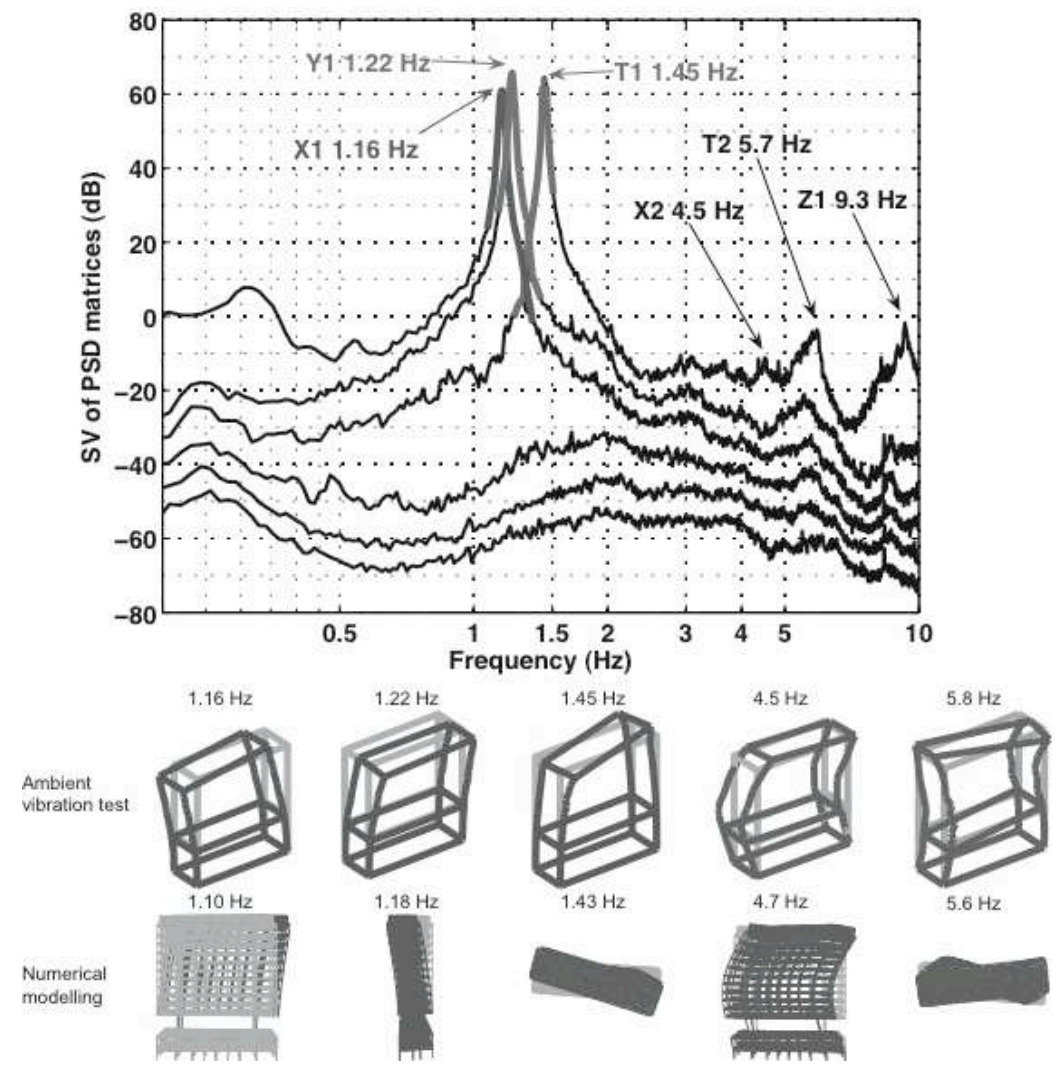

Figure 1: Example of the six first singular values of the Power Spectral Density matrices (upper row) and the corresponding modes assuming a MAC value greater than $80 \%$, extracted from ambient vibration recordings of the City-Hall building of Grenoble and comparison with a numerical model (bottom) (adapted from Michel et al. [19]). 
$\{U(t)\}$ of all the storeys of the model forced into vibration by the ground motion displacement $\left\{U_{s}(t)\right\}$ can be written as follows [38]:

$$
\begin{gathered}
\{U(t)\}=[\Phi]\{y(t)\}+U_{s}(t) \\
\forall j \in[1, M] \quad y_{j}(t)=\frac{-p_{j}}{\omega^{\prime}} \int_{0}^{t} U_{s}^{\prime \prime}(\tau) e^{-\zeta_{j} \omega_{j}(t-\tau)} \sin \left(\omega^{\prime}(t-\tau)\right) d \tau
\end{gathered}
$$

with $\omega_{j}^{\prime}=\omega_{j} \sqrt{1-\zeta_{j}^{2}}$ the damped angular frequency and $p_{j}=\frac{\left\{\Phi_{j}\right\}^{T}[M]\{1\}}{\left\{\Phi_{j}\right\}^{T}[M]\left\{\Phi_{j}\right\}}=$ $\frac{\sum_{i=1}^{N} \Phi_{i j}}{\sum_{j=1}^{M} \Phi_{i j}^{2}}$ the participation factor of mode $j(\mathrm{M}=$ number of modes; $\mathrm{N}=$ number of storey) and assuming an identical mass $M_{i}$ at each storey $i$. $\Phi, \zeta$ and $\omega$ are the $M$ modal parameters of the building (mode shapes, damping ratios and frequencies) and $p$ is the modal participation factor. Eq. 2 is the change of basis from the usual basis to the modal basis and Eq. 3 is known as the Duhamel integral. This formulation assumes linear behaviour and it depends only on modal parameters, excluding other information such as mass and stiffness distribution in the structure. This simple model has been validated during moderate ground motion recordings in buildings by comparing experimental data and numerical modelling $[19,24]$. This simple model reproduces most of the building motion, although torsion and soil-structure interaction are not accounted for in the city scale vulnerability assessment. 


\subsection{Step 2 - Damage parameter: maximum inter-storey (I-S) drift}

In common vulnerability analysis methods [7], [13], [39], damage level is generally related to inter-storey (I-S) drift $D_{i}$ defined below:

$$
D_{i}(t)=\frac{U_{i+1}(t)-U_{i}(t)}{x_{i+1}(t)-x_{i}(t)}
$$

where $i$ is the floor ( 0 is the ground floor) and $x_{i}$ is its position on the vertical axis. $D_{i}$ is related to the mean shear strain over one storey of the structure. Calvi [40] and HAZUS [42] give I-S drift $D_{i}$ thresholds corresponding to the different grades of damage (i.e. slight, moderate, extensive, complete) and for different classes of buildings (Tab. 1). HAZUS values represent state-of-the-art knowledge in terms of earthquake resistance of buildings in the United States, mostly obtained using Pushover modelling. In this study, and because of a lack of knowledge, the classes of RC buildings in France will be assumed to have a similar level of resistance as US RC structures with a comparable structural design for low level of seismic design. For masonry buildings and slight damage, HAZUS [42] gives an I-S drift value of $2 \times 10^{-3}$ for US classes, while Calvi [40] gives $10^{-3}$ for European masonry building classes. This value will be used in our study because of the similarities between French and European masonry techniques. These limits and their uncertainties are clearly a key point that will require improvement in the laboratory and in situ 
Table 1: Inter-story drift limits for Immediate Occupancy limit state (or Slight Damage) extracted from Calvi [40] and HAZUS [42] for the different building types found in Grenoble City (France). Description of typologies is given Tab. 3.

\begin{tabular}{ccc}
\hline Structural type & Grenoble Type & I-S Drift limit \\
\hline RC Shear walls & B4,B5,B6 & $4 \times 10^{-3}$ \\
RC Infilled frames & B1,B2,B3,B5b & $3 \times 10^{-3}$ \\
Masonry (Unreinforced) & M1-M13 & $10^{-3}$ \\
\hline
\end{tabular}

experiments, especially in moderate seismic regions in Europe, where knowledge of the resistance of existing buildings is very incomplete.

\subsection{Step 3 - Fragility curve estimate}

A fragility curve expresses the conditional probability $P[D=j \mid i]$ that a building exceeds a given damage state $j$ for a given level of shaking $i$. It is usually expressed by the cumulative distribution function of a lognormal distribution [41], [13], [42]. Goodman [43] showed that this distribution was the most appropriate in case of limited available data. A large set of ground motion parameters can be found in the literature for predicting damage using maximal ground motion values (e.g., Peak Ground Acceleration PGA or Peak Ground Velocity PGV), or a function of seismic ground motion energy (e.g., Cumulative Absolute Velocity, Arias 
intensity) for which relevant correlations with damage have been observed. Design codes and enhanced vulnerability methods generally use spectral values. Since it is assumed that damage is best correlated with displacement demand, most mechanical methods [7], [13] use spectral displacement $S_{D}$. It can be extracted from design spectra or computed from full waveforms. An interesting advantage of ambient vibration recordings compared to basic modelling is that $S_{D}$ is computed at the experimental fundamental frequency of the structure and for the corresponding experimental damping ratio. This allows decreasing uncertainty related to displacement demand, which is highly frequency-dependent, up to the slight damage grade.

The lognormal distribution is defined by a median value $S_{D, d s}$ and the corresponding lognormal standard deviation $\sigma$. We propose two methods for estimating $S_{D, d s}$ and $\sigma$, corresponding to the slight damage level $d s$. Method 1 uses the full experimental 1D modal model described in the previous section and method 2 is a simplified approach which assumes that only the first mode contributes to the building motion. The advantage of developing a simplified approach lies in reducing computation costs by reducing the building model and the seismic input motion to the fundamental mode parameters.

The standard deviation of the fragility curve $\sigma$ includes different contributions 
for a single building or a building class. In both cases, it includes the uncertainties in the ground motion parameter $\sigma_{G M P}$. This aleatory uncertainty expresses the ability of the chosen demand parameter (PGA, $S_{D}$, etc.) to predict the building response but does not account for uncertainties on the ground motion itself. For risk analysis, i.e. including hazard and vulnerability, the variability of the seismic ground motion must be included in the hazard analysis [44] and the variability of the building response to the same ground motion amplitude (e.g., the same PGA may produce two different displacements) in the fragility curve. The second source of uncertainties is related to the structural modelling. In the single building case, this contribution is mainly epistemic and includes contributions of the response $\sigma_{M R}$ and the I-S drift threshold value corresponding to the damage grade $\sigma_{M D, d s}$. By using models based on experimental values and taking higher modes into account, the epistemic uncertainties on response $\sigma_{M R}$ are reduced and negligible compared to the uncertainties on I-S drift threshold $\sigma_{M D, d s}$. In the building class case, the classification of the buildings into a vulnerability class and the assignment of a generic behaviour type to each class of building is the dominating uncertainty [12]. Since the seismic vulnerability assessment methods need to group buildings for pragmatism, the uncertainty may be considered as apparent aleatory [45]. Nevertheless, it comes from a lack-of-knowledge and can, in theory, be reduced by decreasing the variability into the class, e.g. by increasing the number 
of classes. It is divided into an uncertainty on the response $\sigma_{M R}$ and on the I-S drift threshold $\sigma_{M D, d s}$ for each class. Even if the contribution of $\sigma_{M R}$ must be, in this case, higher than previously, it will also be supposed as negligible compared to $\sigma_{M D, d s}$. Considering the uncertainty sources as lognormal and independent [41], $\sigma$ is therefore given by:

$$
\sigma^{2}=\sigma_{G M P}^{2}+\sigma_{M R}^{2}+\sigma_{M D, d s}^{2}
$$

\subsubsection{Method 1 - Using experimental 1D modal modelling}

To establish the fragility curves of buildings, we considered the dynamic response of the structure subjected to numerous ground motions (Fig. 2). The first step was to select a large set of ground motion time-histories, covering a wide range of ground motions (from weak to strong). In moderate seismic regions, several procedures are available for selecting data: taking data from ground motion databases such as the European strong motion database [46], importing ground motion data from other well-instrumented countries with a high seismic level (Japan, U.S., etc.), or simulating seismic ground motions.

The conditional probability of exceeding the slight damage grade $d s$ for a given level of ground motion, quantified here by $S_{D}\left(f_{1}\right)$, was computed by forcing the $1 \mathrm{D}$ building model into vibration using $n$ synthetic ground motions described hereafter and considering the 1D building elastic response using the Duhamel integral (Eq. 


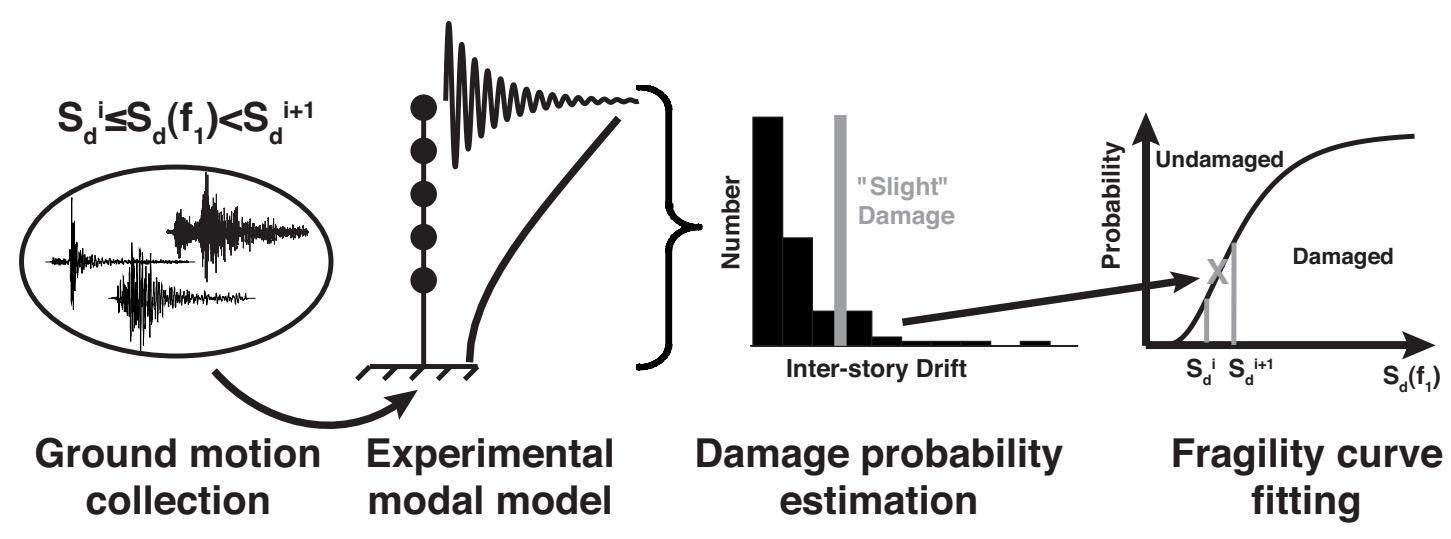

Figure 2: Scheme of the method 1 to estimate the fragility curve corresponding to the slight damage and using the modal model given by ambient vibration experiment.

2 to 3$)$. For each range $i$ of $S_{D}\left(f_{1}\right)\left(S_{D} \in\left[S_{D i}, S_{D i+1}\right]\right)$, we considered at least $n_{i} \geqslant 15$ accelerograms (Fig. 2). The number of runs exceeding the drift limit corresponding to slight damage $d s$ lead then to the probability $P[d \geqslant d s]$. This probability, associated with the ground motion level (mean of the considered $S_{D}$ class at the fundamental frequency $f_{1}$ of the building) is the point of the slight damage fragility curve that separates the undamaged from the damaged state of the building, considered here as the end of the elastic domain of building behaviour. By this method, all the experimental modes are accounted for. The same process was reproduced on different classes of $S_{D}$. Without considering uncertainties on the modelling, the standard deviation obtained with this procedure is the aleatory part $\sigma_{G M P}$ 
The uncertainty on I-S drift limits $\sigma_{M D, d s}$ is unfortunately not provided by HAZUS or in the literature. In this study, we assumed a value of $\sigma_{M D, d s}=$ 0.35. This value corresponds to the assumption that one damage grade cannot be mistaken for another. The distribution of I-S drifts corresponding to slight damage should not therefore exceed with a confidence of $97.5 \%$ the moderate damage limit value. Since $95 \%$ of a normal distribution is located between the mean plus or minus two standard deviations, the following standard deviation can be calculated:

$$
2 \sigma_{M D, d s}+\log \left(S_{D, d s}\right)=\log \left(S_{D, d s+1}\right) \Rightarrow \sigma_{M D, d s}=\frac{1}{2} \log \frac{S_{D, d s+1}}{S_{D, d s}}
$$

If the I-S drift limit of moderate damage is twice the value of slight damage, as it is the case in HAZUS, this leads to $\sigma_{M D, d s}=\log (2) / 2=0.35$. Additional knowledge relating to uncertainties should be included in the method in the future.

\subsubsection{Method 2 - Simplified equation based on the first mode}

In many cases, the response of buildings can be reduced to the response of their first mode in each direction. Using Eq. 2 to 3, we can obtain the relationship between the I-S drift $D_{i}$ at each storey $i$ and the first derivative of the first modal shape $\Phi$ : 


$$
\forall i \in[0, N] \quad D_{i}(t)=\sum_{j=1}^{M} \frac{\Phi_{(i+1) j}-\Phi_{i j}}{x_{i+1}-x_{i}} y_{j}(t) \approx \frac{d \Phi_{1}}{d x}(i) y_{1}(t)
$$

Maximum I-S drift $D_{i}^{\max }=D_{d s}$ can be re-written as a function of the displacement response spectrum $S_{D}\left(f_{1}\right)$ at the fundamental frequency $f_{1}$ and damping $\zeta_{1}$ of the structure extracted from FDD analysis, and the corresponding participation factor $p_{1}$ :

$$
\forall i \in[0, N] \quad D_{i}^{\max }(t) \approx \frac{d \Phi_{1}}{d x}(i) \max \left(y_{1}(t)\right)=\frac{d \Phi_{1}}{d x}(i) p_{1} S_{D}\left(f_{1}, \zeta_{1}\right)
$$

Based on ambient vibrations, we can then deduce the median value of the fragility curve corresponding to the slight damage grade $S_{D, d s}$ from the following relationship:

$$
\forall i \in[0, N] \quad S_{D, d s}\left(f_{1}, \zeta_{1}\right)=\frac{D_{d s}}{p_{1} \max \left(\frac{d \Phi_{1}}{d x}\right)_{i \in[0, N]}}
$$

According to the HAZUS guidelines [42], the lognormal standard deviation of the fragility curves $\sigma=0.7$ was chosen for this method, which could be refined in future studies. Although still based on the experimental behaviour of existing buildings, method 2 does not require intensive computations. As a comparison, the HAZUS method uses the formula:

$$
S_{D, d s}=\frac{D_{d s} H}{p_{1}}
$$


where $H$ is the height of the building. It assumes that drift is uniformly distributed throughout the building. Conversely, the proposed method is able to improve drift distribution through the height of the building and take into account structural irregularities like soft storeys. However, in case of high-rise buildings, for which higher modes may contribute significantly to the building response, the damage probability will be under-estimated since only the fundamental mode is considered.

\section{Application to three RC buildings in Grenoble}

The city of Grenoble in the French Alps is one of the most exposed cities in France. Its population is 160,000 (300,000 including the suburbs) and its economic and industrial activities are mainly related to the high-technology sector. A large number of chemical and nuclear facilities are located in the area. According to the national seismic code [47], the Grenoble region is classified in zone Ib corresponding to $a_{N}=0.15 \mathrm{~g}$. Revision of the national seismic zone map according to the probabilistic approach for European harmonization purposes places Grenoble among the most seismic-prone areas of France $\left(a_{g}=0.16 g\right.$ for the French national annex of EC8). Three structures were considered for application of the seismic vulnerability assessment methods developed in this paper: Mont-Blanc Tower, Arpej I building and Grenoble city hall (Fig. 3). 

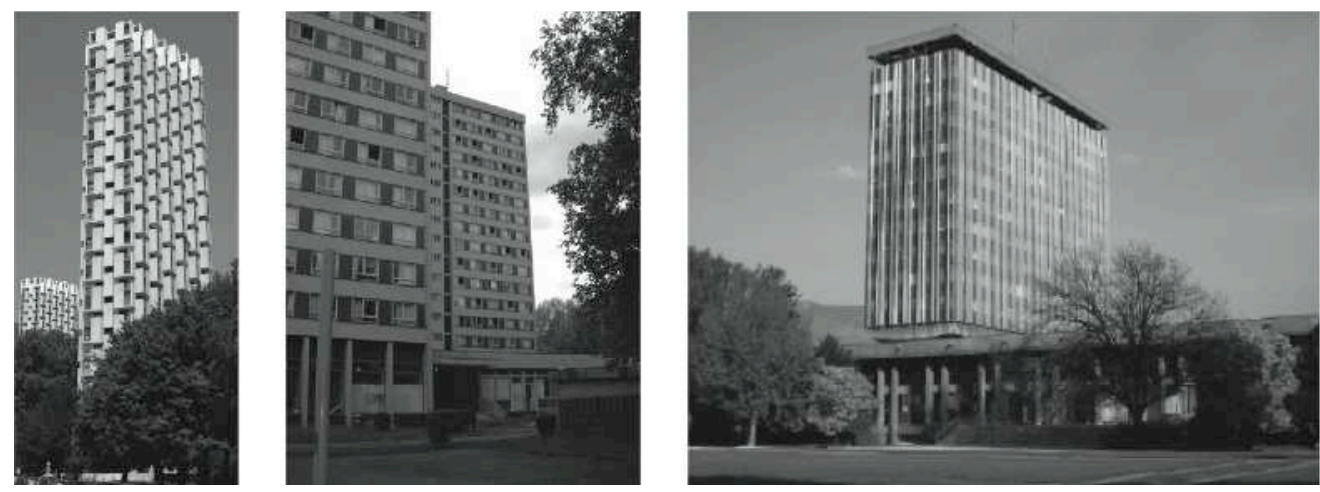

Figure 3: General view of the Mont-Blanc Tower (MBT, left), the ARPEJ Tower (AT, centre) and the Grenoble City Hall building (CHB, right).

\subsection{Description of the buildings}

Mont-Blanc Tower (MBT) is one of the three towers in Ile Verte. These towers are 30-storey RC buildings built between 1963 and 1967. At the time, they were the tallest buildings in Europe $(H=105 m)$. The structure is a rhombus of $40 \times 20 \mathrm{~m}$, the structural strength system is made of two main RC shear walls, continuous throughout their height, completed by small $\mathrm{RC}$ walls in the two horizontal directions. While for city hall, lateral resistance is mainly supported by two inner cores providing exactly the same stiffness in both horizontal directions, Mont-Blanc tower has two disconnected systems for lateral resistance.

Arpej tower (AT) is one of the two twin 16-storey RC buildings $(\mathrm{LxTxH}=28 \times 12 \times 56$ m) built in the 1970s on Grenoble University campus. The inter-storey height is regular between the $2^{\text {nd }}$ and $16^{\text {th }}$ floors $(3.3 \mathrm{~m})$ and larger on the first floor $(5.5$ 
$\mathrm{m})$. Its structure is based on an $\mathrm{RC}$ frame with $2 \mathrm{RC}$ shear walls at the ends in the transverse direction and an $\mathrm{RC}$ shear wall core for lift shafts and stairwells. This building has the most irregular lateral resistance system.

City Hall building (CHB), fully described in Michel et al. [19], is a 13-storey RC building, built in 1967 ( $\mathrm{LxTxH}=44 \times 13 \times 52 \mathrm{~m})$. The inter-storey height is regular between the $3^{\text {rd }}$ and $12^{\text {th }}$ floors $(3.2 \mathrm{~m})$ and larger on the $1^{\text {st }}(4.68 \mathrm{~m})$ and $2^{\text {nd }}$ storeys $(8 \mathrm{~m})$, above which there is a prestressed slab with a $23 \mathrm{~m}$ span, supported by two inner cores. These cores, consisting of RC shear walls, enclose the stairwells and lift shafts and are located at the two opposite sides of the building. Michel et al. [19] assumed that the lateral resistance system was mainly supported by these two inner cores.

These structures were not designed to resist earthquakes and the original design report was not available to the authors.

\subsection{Experiment and modal analysis}

In each building, a temporary experiment was performed to determine the modal model. Ambient vibrations were recorded on each floor with a Cityshark II (18 synchronised channels) 24-bit acquisition system [27] connected to 6 Lennartz 3D 5s seismometers, having a flat response between 0.2 and 50Hz. Several $15 \mathrm{~min}$ datasets were recorded at a frequency rate of $200 \mathrm{~Hz}$ in each building, with one 
reference sensor on the top floor. This provides a reference point to normalize and combine all the components of the modal shape [24]. We used the Frequency Domain Decomposition method (FDD) [35] to evaluate the modal parameters of the structures (frequencies, damping and mode shapes). FDD results are displayed in Fig. 4.

For the MBT building, we found 6 transverse modes and 3 longitudinal modes. The transverse modes correspond to $0.65,2.71,5.9,9.2,13.5$ and $17 \mathrm{~Hz}$ (only the first three will be used in the next section) and longitudinal modes at $0.85,3.26$ and $6.9 \mathrm{~Hz}$. For the AT building, 3 modes were found at 1.17, 4.48, 9.03Hz and $1.31,5.10,10.35 \mathrm{~Hz}$ in the transverse and longitudinal directions respectively. For CHB, extensive ambient vibration experiments were performed and compared to numerical models of building behaviour based on the structural design information [19]. Several modes were excited enough to be determined, the most excited being at $1.22 \mathrm{~Hz}$ in the transverse direction and 1.16 and $4.5 \mathrm{~Hz}$ in the longitudinal direction. Michel et al. [19] also showed a good fit between the experimental model based on ambient vibrations and the 3D numerical model developed for assessing the elastic response of existing structures.

The MBT is twice as tall as the two other buildings, which explains its considerably lower fundamental frequencies. The damping ratios of MBT and CHB are around $1 \%$ and around $1.5 \%$ for AT. These low values are commonly found for such build- 
ings under ambient vibrations. They may increase with the shaking amplitude [48] but moderately up to slight damage. Compared to theoretical shear and cantilever beams usually considered in order to analyse the building behaviour, we observe (Fig. 5) that the MBT, CHB and AT experimental behaviours fall between the two theoretical continuous beam behaviours. The load-bearing system of MBT is stiffer with respect to the floors than the load-bearing systems of AT and CHB. These behaviours conform to the structural shear resistance observed in the three building: the resistance system of MBT is mainly supported by RC shear walls while $\mathrm{AT}$ and $\mathrm{CHB}$ have combined RC shear walls and frames, adding a slight shear component to their behaviour. In the following, the three buildings will be considered as belonging to the $\mathrm{C} 2$ class of the FEMA typology.

\subsection{Hazard and fragility curves}

The three buildings were built in the late 1960s, without any seismic design code but according to specific designs for tall buildings. Therefore, they are associated with the Low Code design class according to the HAZUS method [42], for which the

I-S drift limit is set at $4 \times 10^{-3}$ (slight damage). Contrary to what is recommend in HAZUS methodology, we did not reduce this value according to building height since the height is already included in our experimental model. Both horizontal directions are considered but only the weaker is used to compute fragility curves. 


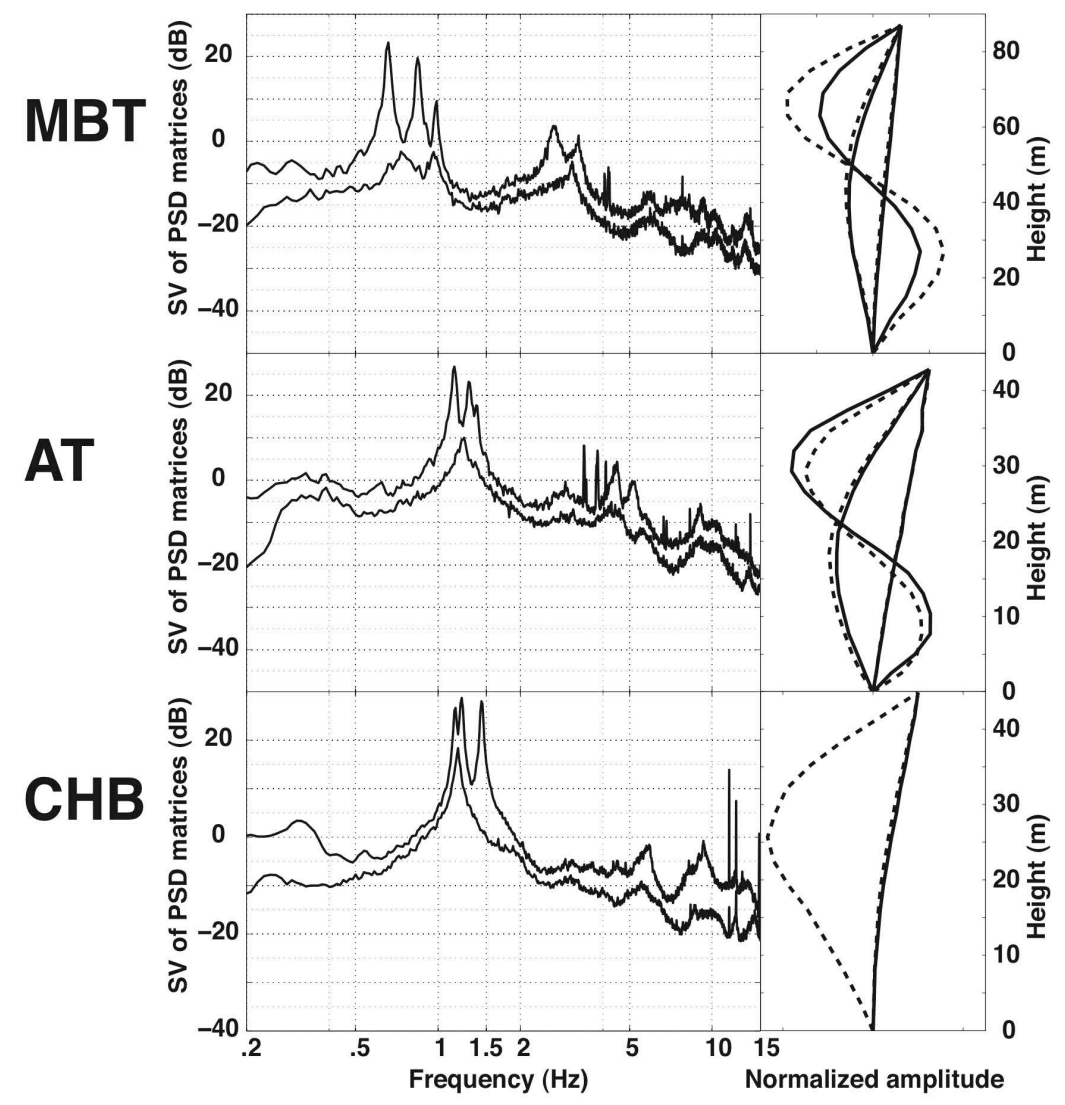

Figure 4: Modal shapes of the Mont-Blanc Tower (MBT), Arpej Tower (AT) and City-Hall Building (CHB) extracted from ambient vibrations and processed using the Frequency Domain Decomposition FDD method. Left: Two first singular value spectra - Right: Shape of the modes detected by the ambient vibrations survey (solid line: transverse direction, dashed line: longitudinal direction). 


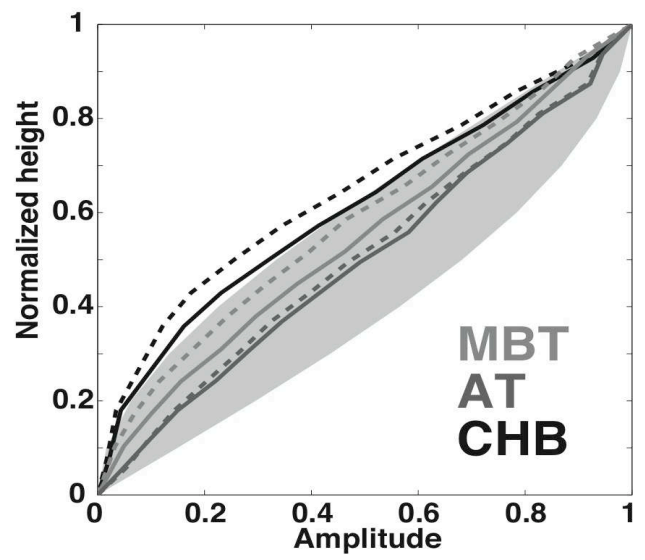

Figure 5: First mode shape of the Mont-Blanc Tower (MBT), Arpej Tower (AT) and City-Hall Building (CHB) extracted from ambient vibrations and processed using the Frequency Domain Decomposition FDD method (solid line: transverse direction, dashed line: longitudinal direction). Theoretical simple beams are displayed in the shaded area between the theoretical bending and shear beams. 
For method 1, the 164 full waveforms extracted from the European strong motion database [46] and described in Lestuzzi et al. [49] were used. For method 2, no further assumption is needed: the medians of the fragility curves are directly computed from Eq. 9 and the standard deviation is set at 0.7 .

The resulting fragility curves are displayed in Tab. 2 and Fig. 6. CHB and AT have the same vulnerability function, regardless of the method used, since they belong the same building class. MBT shows differences due to its height. Moreover, some differences exist between the two methods. The first reason is that Method 2 may overestimate vulnerability for any building, due to neglect of the higher modes. This difference is more significant for MBT. The second reason is that the $\sigma$ value considered for method $2(\sigma=0.7)$ is higher than $\sigma$ values computed by method 1 , which are around 0.4 (quadratic addition of $\sigma_{M D, d s}=0.35$ and $\sigma_{G M P}$ whose value is found to be around 0.2). This can be justified since epistemic uncertainties are reduced by including higher modes in the total building response. In this case, the $\sigma_{M D, d s}=0.35$ is mostly controlling the final standard deviation value so that the results are very similar. In comparison, the same fragility curves computed as a function of peak ground acceleration instead of spectral displacement give a higher $\sigma_{G M P}$ value of around 0.5 .

Comparison with C2 class HAZUS fragility curves (Eq. 9) shows similar results for AT and CHB structures, even if the I-S drift limit is arbitrarily divided by 2 in 


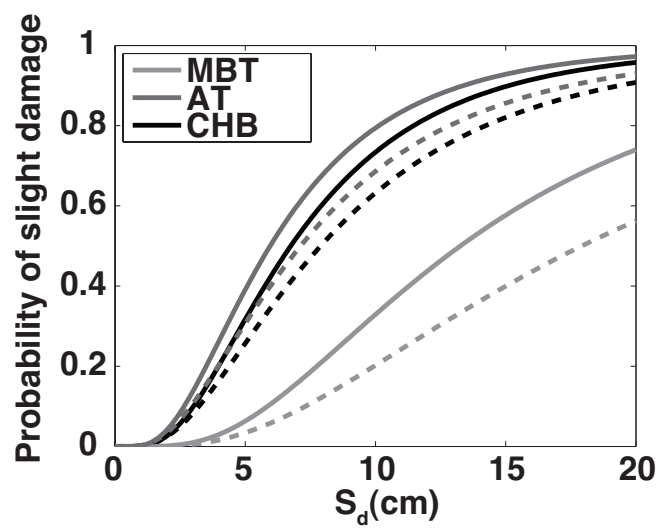

Figure 6: Fragility curve of the damage state Slight for the Mont-Blanc Tower (MBT), Arpej Tower (AT) and City-Hall Building (CHB) using Method 1 accounting for the building higher modes (solid lines) and Method 2 including only the fundamental mode (dashed lines).

Table 2: Median value of $S_{D, d s}$ and the corresponding lognormal standard deviation $\sigma$ of the fragility curves (slight damage $d s$ ) of the Mont-Blanc Tower (MBT), Arpej Tower (AT) and City-Hall Building (CHB) computed using the two methods shown in this paper and the HAZUS method (Eq. 9).

\begin{tabular}{cccccc}
\hline Fragility curve (slight damage) & Method 1 & \multicolumn{3}{c}{ Method 2 } \\
\hline Building & Median (cm) & $\sigma$ & Median $(\mathrm{cm})$ & $\sigma$ \\
CHB & 6.7 & 0.40 & 7.9 & 0.7 \\
MBT & 13.3 & 0.41 & 17.9 & 0.7 \\
AT & 6.0 & 0.40 & 7.3 & 0.7 \\
\hline
\end{tabular}


the HAZUS method to account for the effects of building height. For MBT, HAZUS underestimates the fragility curve given using method 1 because of higher mode effects. We may assume that within the same building class, experimental modal models may help to improve the vulnerability assessment of existing buildings by reducing epistemic uncertainty due to the assignment of a generic behaviour type (analytical model) to a class of building, without any assumption regarding structural design, ageing effects or resistance frame.

\section{Analysis of seismic risk in Grenoble}

The urban development of Grenoble (France) started in around 450 BC and it remained a small town until the end of the 19th century. 1945-1970 was definitely the start of population growth: within 11 years (1954-1965), the number of dwellings doubled (from 47,000 to 94,000). Construction rates then continued to increase (1000 per year in 1954, 3000 until 1962 and 4500 in 1965). A detailed description of the urban development of the city can be found in Guéguen et al. [11]. Guéguen and Vassail [50] made reference to various building typologies and their distribution throughout the city, accounting for local practices, successive modifications of the French design code and history. Their conclusions are: the old city centre consists of stone and brick masonry buildings; the suburban districts are mainly made of reinforced concrete, RC frames before 1965 and RC shear walls 
after 1970; the expansion suburbs are very heterogeneous, mixing individual housing and multi-storey buildings, with reinforced concrete and masonry structures, all built over a long period. Consequently, most of the medium-rise buildings were built during the 1945-1970 period, before application of the national seismic code, and this is the dominant typology in Grenoble. The building typology matrix of Grenoble was provided by [50] with equivalent classifications in the European Macroseismic Scale typology (Tab. 3). The potential gains of using ambient vibrations are illustrated in the example in Fig. 7. The first mode of a masonry class with an RC slab (MA10) or a wooden slab (MA1) evaluated using ambient vibrations is compared with the theoretical shear and cantilever beam usually employed for predicting the behaviour of existing buildings. Cantilever (top limit of the shaded area on Fig. 7) and shear (bottom limit of the shaded area) beams are extreme cases of elastic deformations for vertically homogeneous structures. The amplitude and distribution of I-S drift in each case is different. We observe that the behaviour of MA10 is close to that of the shear beam, for which the slabs are stiffer than the walls, and MA1 behaves like the cantilever beam, whose slabs are softer than the walls. It is therefore possible to allocate a generic behaviour model to each class by using ambient vibrations in buildings, and thereby reducing the epistemic uncertainties due to model attribution. Following the procedure defined above, the slight damage fragility curves of each class of the Grenoble typology 


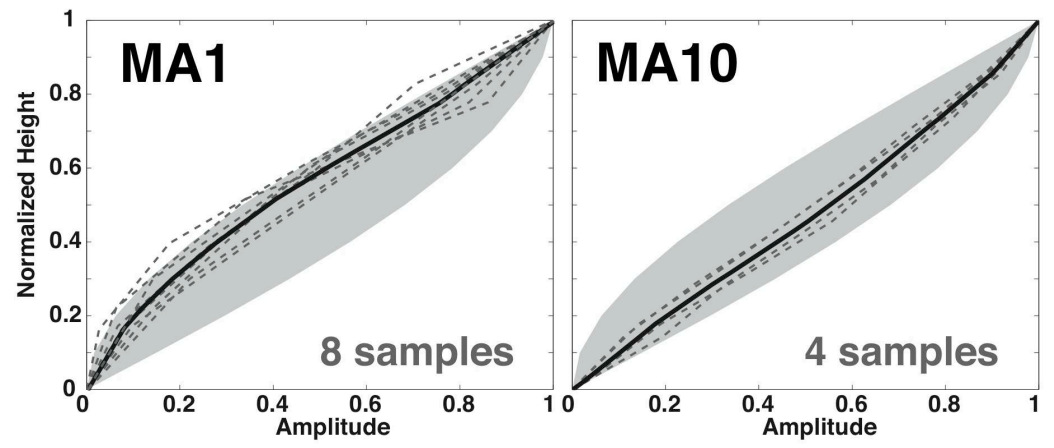

Figure 7: First mode of the MA1 (Masonry building with wooden floors) and MA10 (Masonry building with RC floors) extracted from ambient vibrations (dashed grey lines), median value (solid black line) and comparison with theoretical shear and cantilever beams (shaded grey area).

are displayed in Fig. 8 for masonry and RC buildings. We observe a greater variability of the fragility curves for RC classes, indicating greater heterogeneity in the quality of such constructions. RC buildings are less vulnerable than masonry buildings. Among the RC classes, the tallest buildings are the least vulnerable. Finally, the distribution of the classes within the city (Fig. 9) was defined into homogenous urban zones, delineated using aerial 3D pictures, and surveyed in the field by random pedestrian course [11].

Analysis of the historical and instrumental seismicity of Grenoble shows that the possibility of earthquakes is at least comparable to that of Annecy-Epagny $\left(M_{w}=5.5,1996\right)$, Corrençon $\left(M_{w}=4.8,1962\right)$ or Chamonix $\left(M_{w} \approx 5.0,1905\right)$. 
Table 3: Building typology matrix (BDT) of the Grenoble city (after [50]) and equivalent classes from Risk-UE, EMS98 and HAZUS methodologies.

\begin{tabular}{|c|c|c|c|c|c|}
\hline Description & BDT & Risk-UE & EMS98 & HAZUS & Code \\
\hline $\mathrm{RC}$ frames $30-50$ th medium rise & BA1 & $\mathrm{RC} 3.1$ & $\mathrm{RC} 1$ & C3 & pre \\
\hline $\mathrm{RC}$ frames $30-50$ th high rise & BA2 & $\mathrm{RC} 3.1$ & $\mathrm{RC} 1$ & C3 & pre \\
\hline $\mathrm{RC}$ frames $30-50$ th low rise & BA3 & $\mathrm{RC} 4$ & $\mathrm{RC} 2$ & C3 & low \\
\hline SW RC 60th & BA4 & $\mathrm{RC} 2$ & $\mathrm{RC} 4$ & $\mathrm{C} 2$ & pre \\
\hline SW RC 70th & BA5 & $\mathrm{RC} 2$ & $\mathrm{RC} 5$ & $\mathrm{C} 2$ & low \\
\hline SW RC after 1980 & BA6 & $\mathrm{RC} 2$ & $\mathrm{RC} 6$ & $\mathrm{C} 2$ & med \\
\hline Rubble stones before 1815 & MA1 & M1.1 & M1 & URM & pre \\
\hline Rubble stones $1815-1870$ labor housings & MA2 & M1.2 & M3 & URM & pre \\
\hline Rubble stones with small reinforcements labor housings & MA3 & M1.2 & M3 & URM & pre \\
\hline Rubble stone XIXth century - middle-class housings & MA4 & M1.2 & M3 & URM & pre \\
\hline Rubble stone with precast decorative element XIXth century & MA5 & $\mathrm{M} 1.2$ & M3 & URM & pre \\
\hline Massive stones & MA6 & M1.3 & M4 & URM & pre \\
\hline Simple stone with RC slab & MA7 & M3.4 & M6 & URM & pre \\
\hline Simple stone with wooden slab before 1914 (labor housings) & MA8 & $\mathrm{M} 1.2$ & M3 & URM & pre \\
\hline Simple stone with RC slab (social housings) & MA9 & M3.4 & M6 & URM & pre \\
\hline Rubble stone with RC slab (high-rise) & MA10 & M3.4 & M6 & URM & pre \\
\hline Rubble stones (low-rise) before 1914 & MA11 & M1.1 & M1 & URM & pre \\
\hline Simple stone with wooden slab before 1950 (low-rise) & M12 & M3.3 & M3 & URM & pre \\
\hline Unreinforced, with manufactured concrete units after 1945 (low-rise) & M13 & M3.4 & M5 & URM & pre \\
\hline
\end{tabular}



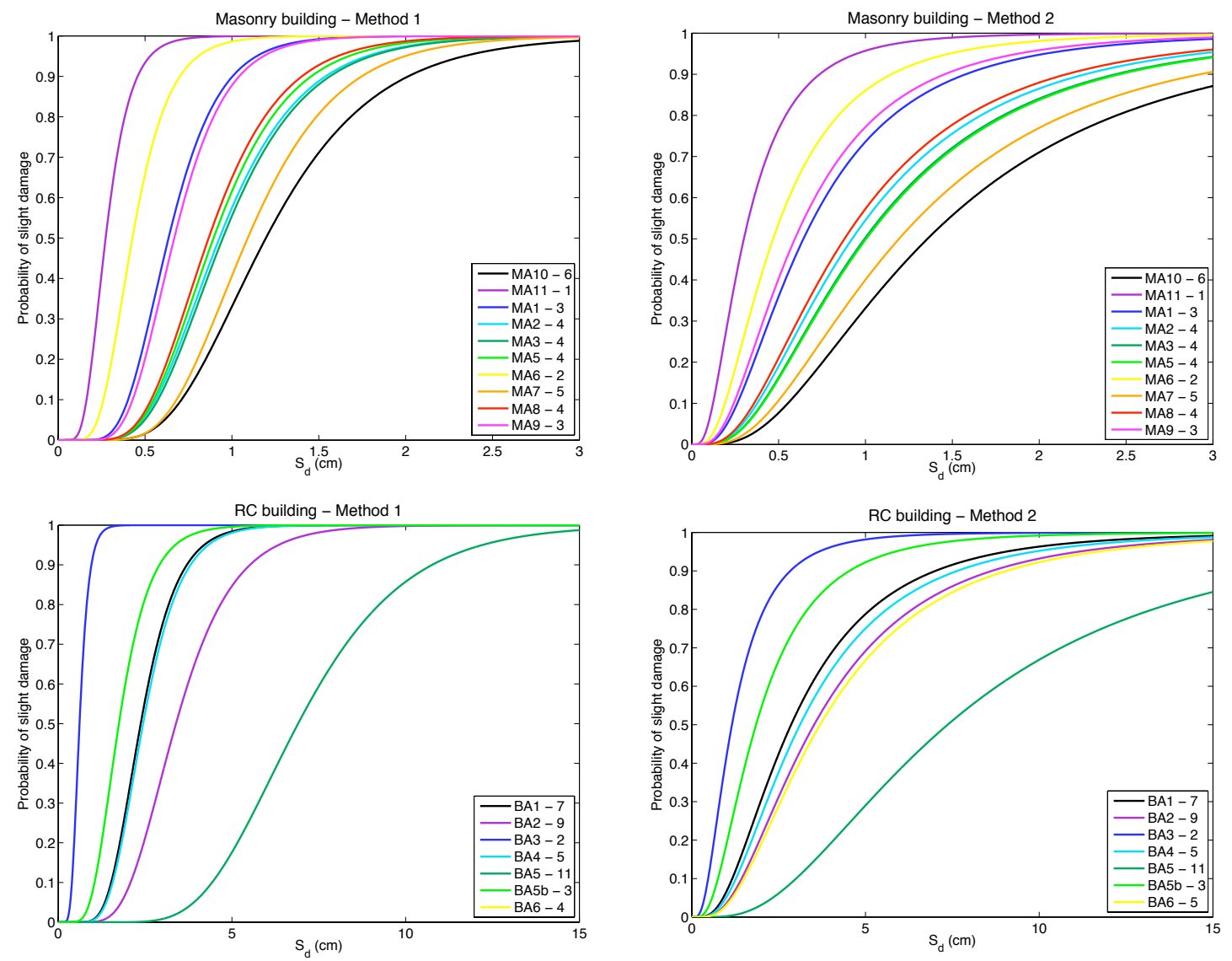

Figure 8: Fragility curves for the median model of the RC (upper row) and Masonry (lower row) buildings of the Grenoble typology and computed using the Method 1 (left) and Method 2 (right). The number on the right column of the legend corresponds to the number of buildings used for getting the median model. 
Such quakes could be located only a few kilometres from the city on a very close active fault at the southeast limit of the basin [51]. Their magnitude could be equal to 5.5 at a distance of $15 \mathrm{~km}$ from the city. Moreover, Grenoble is founded on a deep Y-shaped sedimentary basin, filled with deep postglacial sediments (several hundred meters of lacustrine sandy-clays) and confined between the stiff Belledonne, Chartreuse and Vercors mountain ranges that produce strong amplification of the seismic ground motion in the city (e.g., [52], [53]). It has been shown that Grenoble site effects are highest in the frequency band corresponding to buildings more than 5 storeys high (between 1 and $5 \mathrm{~Hz}$ ), which represents most of the buildings in Grenoble. In order to assess the seismic risk of Grenoble, we considered the following seismic ground motion scenario: a $M_{w}=5.5$ earthquake located on the Belledonne Border fault, simulated using the Empirical Greens Function (EGF) method. Ground motion is then simulated by summing up at a given site small earthquake recordings, referred to as EGF, obtained at the same site. Thus this method automatically accounts for specific site effects, under the assumption of the linearity of the soil response. We used the technique described in Causse et al. [54], in which aleatory ground motion variability is accounted for by assuming probability density functions of source parameters (stress drop, location of the rupture nucleation and rupture velocity). We used the Lancey earthquake as $\operatorname{EGF}\left(01 / 01 / 2001, M_{L}=2.3\right)$ recorded by the OGDH accelerometric station 
of the French Accelerometric Network (RAP, [55]) and located downtown in the immediate vicinity of $\mathrm{CHB}, 15 \mathrm{~km}$ from the hypocenter (source-station azimuth $265^{\circ}$ ). The procedure than provides a set of ground motion time-histories, representing the source variability and accounting for propagation and local site effects. In our study, the full waveforms contain the specific site condition effects due to the Grenoble basin, with amplification of seismic ground motion in the frequency band $[1-30 \mathrm{~Hz}]$ corresponding to the higher modes of Grenoble buildings. Note, however, that we used a single EGF. Ground motion spatial variability due to spatially variable site effects is thus not accounted for. Spatial variations on hazard was not accounted for in order to focus the conclusions on the vulnerability. In a future work, we could use different EGF recorded at different sites within the basin (e.g. Causse et al. [56]) accounting therefore for correlated spatial variability in order to perform a realistic scenario.

The number of structures suffering at least slight damage throughout the city is displayed in Fig. 9. Unlike the results of an empirical study [11] or a scenario that does not include site effects, the vulnerable city centre (stone masonry buildings) is not the most damaged zone in terms of slight damage. Indeed, seismic demand is highest for RC buildings, due to the strong site effects included in the EGF scenario, producing amplification in the frequency band of most RC buildings. Thus, the damage distribution in the city is more complex than with a simple sce- 
nario based on a code-based response spectrum. However, the methods developed here only compute the slight damage grade. The distribution of higher damage grades may be different since the displacement capacity of RC structures is higher. Moreover, method 1 accounts for higher modes of the tallest structures, i.e. RC structures, giving a higher rate of damaged RC buildings compared to method 2 .

\section{Conclusion}

In their review of seismic vulnerability assessment methodologies, Calvi et al. [3] concluded that (1) a new seismic vulnerability method must integrate a more enhanced definition of the seismic hazard definition (full waveform, probabilistic hazard), (2) the source of uncertainties should be specified and then reduced, (3) the epistemic uncertainties must be reduced by defining a model that could be easily adapted to different building designs around the world and (4) the method must be well-adapted to the number of buildings and provide the same degree of confidence as in the assessment. They also concluded that most of the methods available fail to meet all these requirements.

The methods developed in this paper help to improve seismic vulnerability assessment by reducing the epistemic uncertainties due to the lack of knowledge in building models. These methods use ambient vibration based methods to adjust 


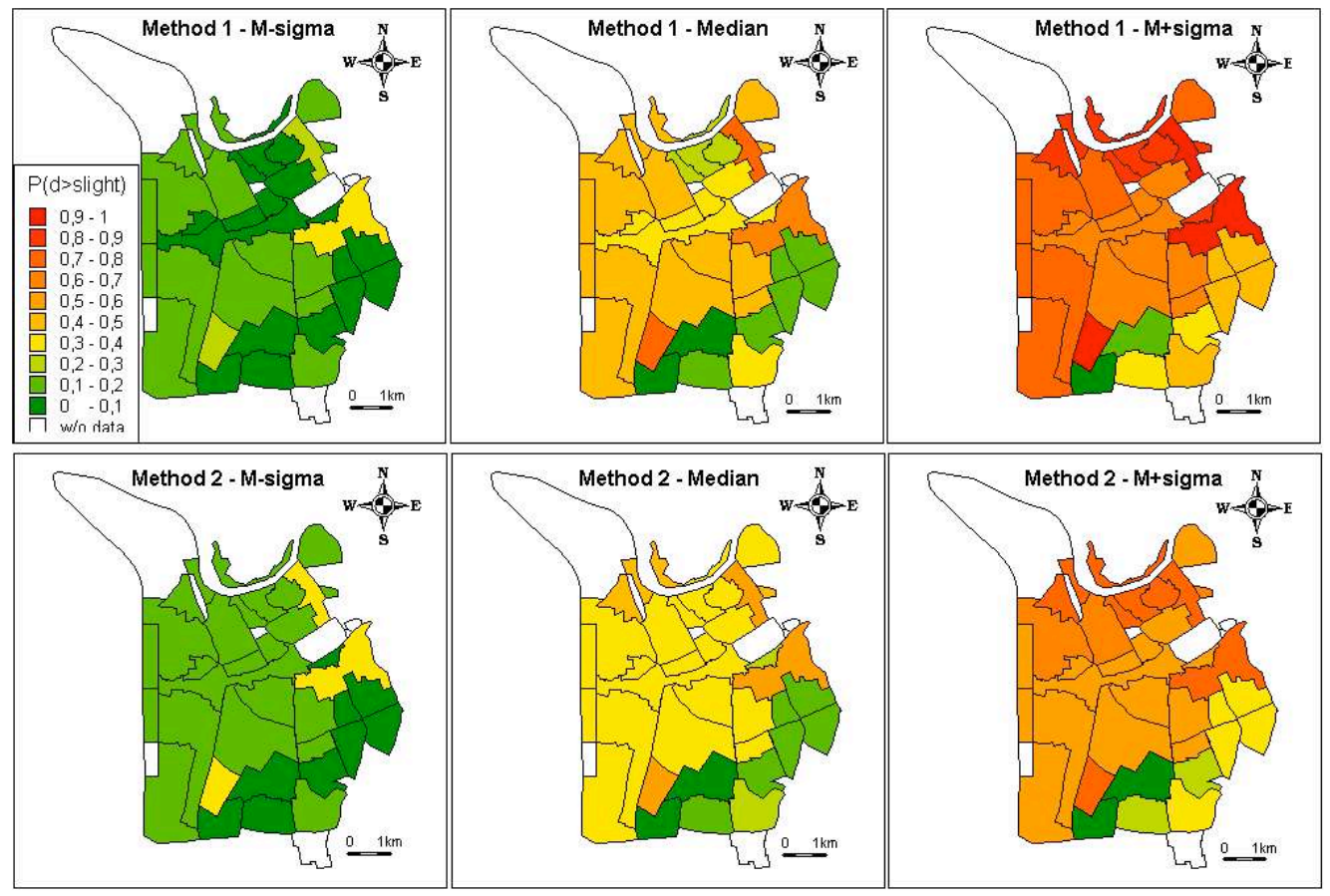

Figure 9: Seismic risk scenario in Grenoble City corresponding to the probability of slight damage produced by $M_{w}=5.5$ earthquake at $15 \mathrm{~km}$ simulated using the Empirical Greens Function (EGF) method [54]. Scenarios are provided for the median estimate +/- sigma of the seismic ground motion including site effects and the source variability. Method 1 (upper row) and Method 2 (lower row) are displayed. 
the building model to realities in the field. The modal model derived therefore allows some design specificities to be taken into account and is adapted to the recent definition of seismic hazard: full waveform or response spectra may be employed to estimate whether or not the building may suffer damage by the end of shaking. Since it is based on ambient vibrations, the model is relevant only for slight damage, considered here as the end of the linear building response. There is no doubt that these methods are rather limited for high seismic regions and efforts must be made to provide fragility curves corresponding to higher damage grades. Nevertheless, countries with a moderate-to-low seismic risk may have suffered strong historical earthquakes causing damage and casualties. They can also be subject to moderate earthquakes causing considerable economic losses. This is the case in France where a major earthquake occurred at the beginning of the 20th century (1909) with significant effects on the rural area of Aix-en-Provence (southeast France). The first damage grade is therefore of great importance in predicting the integrity of structures for which post-seismic feedback is available. Moreover, the slight damage grade has aroused interest in the community, centered on the topic of geothermal quakes [29]. For example, correct estimation of slight damage due to small but nearby earthquakes in urban areas and subjected to site effects is necessary to enable estimation of the risk of geothermal projects [57]. In 2009 in Basel (Switzerland), more than $\$ 9$ millions damages, slight damages only, were 
induced by the Deep Heat Mining project [29], [58]. The proposed method may be particularly adapted to mitigate this kind of risk and the case of Basel may be a excellent case-study.

\section{Acknowledgements}

This work has been supported by French Research National Agency (ANR) through RGCU program (project ARVISE nANR-06-PRGCU-007-01) and by the VULNERALP project of the Rhône-Alpes regional council.

\section{References}

[1] Eurocode 8 Design of structures for earthquake resistance - Part 1: General rules, seismic actions and rules for buildings. European Committee for Standardization, EN 1998-1, 2004.

[2] Coburn A., Spence R. Earthquake protection. (2nd edn). John Wiley and Sons, Ltd, 2002.

[3] Calvi G., Pinho R., Magenes G., Bommer J., Restrepo-Velez L., Crowley H. Development of seismic vulnerability assessment methodologies over the past 30 years. Indian Society Journal of Earthquake Technology 2006; 43(3):75-104. 
[4] Whitman R., Reed J., Hong S.-T. Earthquake damage probability matrices. In 5th World Conference of Earthquake Engineering (WCEE) Vol2, pp 25312540, Rome, Italy, 1973.

[5] Benedetti D., Petrini V. On seismic vulnerability of masonry buildings: proposal of an evaluation procedure. LIndustria delle Costruzioni 1984; 18: 66-78.

[6] GNDT. Instruzioni per la Compilazione de lla Sceda di Relivamento Esposizione e Vulnerabilit Sismica Degli Edifici. Gruppo Nazionale per la Difesa dai Terremoti, Regione Emilia Romagna y Regione Toscana, Italy, 1986.

[7] FEMA. HAZUS99 Technical Manual Federal Emergency Management Agency, Washington, DC, U.S.A., 1999.

[8] Lagomarsino S., Giovinazzi S. Macroseismic and mechanical models for the vulnerability and damage assessment of current buildings. Bulletin of Earthquake Engineering 2006; 4:415-443.

[9] Steimen S., Faeh D.,Giardini D.,Bertogg M.,Tschudi S. Reliability of building inventories in seismic prone region. Bulletin of Earthquake Engineering 2004; 2(3):361-388.

[10] Roca A., Goula X., Susagna T., Chavez J., Gonzalez M., Reinoso E. A simplified method for vulnerability assessment of dwelling buildings and estimation of 
damage scenarios in Catalonia, Spain. Bulletin of Earthquake Engineering 2006; $4(2): 141-158$.

[11] Guéguen P., Michel C., LeCorre L. A simplified approach for vulnerability assessment in moderate-to-low seismic hazard regions: application to Grenoble (France). Bulletin of Earthquake Engineering 2007; 5(3):467-490.

[12] Spence R., Bommer J., Del Re D., Bird J., Aydinoglu N., Tabuchi S. Comparing loss estimation with observed damage: a study of the 1999 Kocaeli earthquake in Turkey. Bulletin of Earthquake Engineering 2003; 1:83-113.

[13] Milutinovic Z.V., Trendafiloski G.S. Risk-UE An advanced approach to earthquake risk scenarios with applications to different european towns. WP4: Vulnerability of current buildings. European Project, 2003.

[14] Boutin C., Hans S., Ibraim E., Roussillon P. In Situ experiments and seismic analysis of existing buildings - Part II: Seismic integrity threshold. Earthquake Engineering and Structural Dynamics 2005; 34(12):1531-1546.

[15] Davison C. Fusakichi Omori and his work on earthquakes Bulletin of the Seismological Society of America 1924; 14(4):240-255.

[16] Clinton J.F., Bradford S.C., Heaton T.H., Favela J. The observed wander of the natural frequencies in a structure. Bulletin of the Seismological Society of America 2006; 96(1):237-257. 
[17] Cunha A., Caetano E. From input-output to output-only modal identification of civil engineering structures. In 1st International Operational Modal Analysis Conference (IOMAC) 2005; Copenhagen, Denmark, pp 11-27.

[18] Volant P., Orbovic N., Dunand F. Seismic evaluation of existing nuclear facility using ambient vibration test to characterize dynamic bahavior of the structure and microtremor measurements to characterize the soil: a case study. Soil Dynamics and Earthquake Engineering 2002; 22:1159-1167.

[19] Michel C., Guéguen P., El Arem S., Mazars J., Kotronis P. Full scale dynamic response of a $\mathrm{RC}$ building under weak seismic motions using earthquake recordings, ambient vibrations and modelling. Earthquake Engineering and Structural Dynamics 2010; doi 10.1002/eqe.948.

[20] Trifunac M. Comparison between ambient and forced vibration experiments. Earthquake Engineering and Structural Dynamics 1972; 1:133-150.

[21] Celebi M., Phan L.T., Marshall R.D. Dynamic characteristics of five tall buildings during strong and low-amplitude motions. The Structural Design of Tall Buildings 1993 2(1):1-15.

[22] Meli R., Faccioli E., Muri-Vila D.,Quaas R.,Paolucci R. A study of site effects and seismic response of an instrumented building in Mexico City. Journal of Earthquake Engineering 1998; 2(1):89-111. 
[23] Hans S., Boutin C., Ibraim E., Roussillon P. In Situ experiments and seismic analysis of existing buildings - Part I: Experimental investigations. Earthquake Engineering and Structural Dynamics 2005; 34(12):1513-1529.

[24] Michel C., Guéguen P., Bard P.-Y. Dynamic parameters of structures extracted from ambient vibration measurements: An aid for the seismic vulnerability assessment of existing buildings in moderate seismic hazard regions. Soil Dynamics and Earthquake Engineering 2008; 28(8):593-604.

[25] Safak E., Celebi M. Analyses of recorded responses of two high-rise buildings during the Loma Prieta earthquake of October 1989. Bulletin of the Seismological Society of America 1991; 81(5):2087-2110.

[26] Dunand F., Meziane Y.A., Guéguen P., Chatelain J.-L., Guillier B., Salem R.B., Hadid M., Hellel M., Kiboua A., Laouami N., Machane D., Mezouer N., Nour A., Oubaiche E., Remas A. Utilisation du bruit de fond pour lanalyse des dommages des bâtiments de Boumerdes suite au séisme du 21 mai 2003. Memoires du Service Geologique Algerien 2004; 12:177-191.

[27] Chatelain J.-L., Guéguen P., Guillier B., Frechet J., Bondoux F., Sarrault J., Sulpice P., Neuville J. Cityshark: A user-friendly instrument dedicated to ambient noise (microtremor) recording for site and building response studies. Seismological Research Letters 2000; 71(6):698-703. 
[28] Guéguen P., Jolivet V., Michel C., Schveitzer A.-S. Comparison of velocimeter and coherent LIDAR measurements for building frequency assessment. Bulletin of Earthquake Engineering 2010; 8(2):327-338, doi: 10.1007/s10518-009-9137-2.

[29] Giardini D. Geothermal quake risks must be faced. Nature 2009; 462:17.

[30] Carder D.S. Observed vibrations of buildings. Bulletin of the Seismological Society of America 1936; 26(3):245-277.

[31] Carden E.P., Fanning P. Vibration based condition monitoring: A review. Structural Health Monitoring 2004; 3(4):355-377.

[32] Peeters B. System Identification and Damage Detection in Civil Engineering. PhD thesis, Katholieke Universiteit Leuven, 2000.

[33] He J., Fu Z.-F. Modal analysis. Butterworth-Heinemann, Oxford, 2001.

[34] Prevosto M. Algorithmes didentification des caractristiques vibratoires de structures mcaniques complexes $\mathrm{PhD}$ thesis, Universit de Rennes, 1982.

[35] Brincker R., Zhang L., Andersen P. Modal identification of output only systems using Frequency Domain Decomposition. Smart Materials and Structures $2001 ; 10: 441-445$. 
[36] Welch P. The use of Fast Fourier Transform for the estimation of Power Spectra: A method based on time averaging over short, modified periodograms. I.E.E.E Transactions on Audio and Electroacoustics 1967; 15(2):70-73.

[37] Brincker R., Ventura C., Andersen P. Damping estimation by Frequency Domain Decomposition. In 19th International Modal Analysis Conference (IMAC) 2001; Kissimmee, Florida, pp 698-703.

[38] Clough R., Penzien J. Dynamics of Structures. Mc Graw-Hill, 1993.

[39] Rosseto T., Elnashai A. A new analytical procedure for the derivation of displacement-based vulnerability curves for population of RC structures. Engineering Structures 2005; 27:397-409.

[40] Calvi G. A displacement-based approach for vulnerability evaluation of classes of buildings. Journal of Earthquake Engineering 1999; 3(3):411-438.

[41] McGuire, R. K. Seismic Hazard and Risk Analysis Earthquake Engineering Research Institute (EERI), Monograph MNO-10, 2004.

[42] FEMA. HAZUS-MH MR3 Technical Manual. Federal Emergency Management Agency, Washington, DC, U.S.A., 2003.

[43] Goodman J. Structural fragility and principle of maximum entropy Structural Safety 1985; 3:37-46. 
[44] Bommer J.J., Crowley H. The Influence of Ground-Motion Variability in Earthquake Loss Modelling Bulletin of Earthquake Engineering 2006; 4:231248.

[45] Bradley B.A. Epistemic Uncertainties in Component Fragility Functions Earthquake Spectra 2010; 26(1):41-62.

[46] Ambraseys N., Smit P., Sibjornsson P., Suhadolc P., Margaris B. Internet site for European strong-motion data. European Commission, Research Directorate General, Environment and Climate Program, 2002.

[47] DTU Rgles PS92. Rgles de construction parasismique 1995. in French.

[48] Celebi M. Comparison of damping in buildings under low amplitude and strong motions Journal of Wind Engineering and Industrial Aerodynamics 1996; 59:309-323.

[49] Lestuzzi P., Belmouden Y., Trueb M. Non-linear seismic behavior of structures with limited hysteretic energy dissipation capacity. Bulletin of Earthquake Engineering 2007; 5:549-569.

[50] Guéguen P., Vassail T. VULNERALP - Typologie de lagglomration grenobloise 2004. 
[51] Thouvenot F., Frechet J., Jenatton L., Gamond J.-F. The Belledonne Border Fault: identification of an active seismic strike-slip fault in the Western Alps. Geophysical Journal International 2003; 155:174-192.

[52] Lebrun B., Hatzfeld D., Bard P.-Y. A site effect study in urban area: experimental results in Grenoble (France). Pure and Applied Geophysics 2001; 158:2543-2557.

[53] Guéguen P., Cornou C., Garambois S., Banton J. On the limitation of the $\mathrm{H} / \mathrm{V}$ spectral ratio using seismic noise as an exploration tool: application to the grenoble valley, a small apex ratio basin. Pure and Applied Geophysics 2007; 64(1):115-134.

[54] Causse M., Cotton F., Cornou C., Bard P.-Y. Calibrating median and uncertainty estimates for a practical use of Empirical Green's Functions technique. Bulletin of the Seismological Society of America 2008; 98(1):344-353.

[55] Pequegnat C., Guéguen P., Hatzfeld D., Langlais M. The French Accelerometric Network (RAP) and National Data Center (RAP- NDC). Seismological Research Letters 2008; 79(1):79-89.

[56] Causse M., Chaljub E., Cotton F., Cornou C., Bard P.-Y. New approach for coupling $k^{-2}$ and empirical Green's functions: application to the blind predic- 
tion of broad-band ground motion in the Grenoble basin. Geophysical Journal International 2009; 179(3):1627-1644.

[57] Bommer J.J., Oates S., Mauricio Cepeda J., Lindholm C., Bird J., Torres R., Marroqun G., Rivas J. Control of hazard due to seismicity induced by a hot fractured rock geothermal project. Engineering Geology 2006; 83(4):287-306, doi: 10.1016/j.enggeo.2005.11.002.

[58] Deichmann N., Giardini D. Earthquakes Induced by the Stimulation of an Enhanced Geothermal System below Basel (Switzerland). Seismological Research Letters 2009; 80(5):784-798, doi: 10.1785/gssrl.80.5.784. 